OPEN ACCESS

Edited by:

Yilong Cheng,

Xi'an Jiaotong University, China

Reviewed by:

Joseph J Richardson,

The University of Tokyo, Japan

*Correspondence:

Jianwu Zhao

jianwu@jlu.edu.cn

Specialty section: This article was submitted to Biomaterials,

a section of the journal

Frontiers in Materials

Received: 25 October 2021

Accepted: 29 November 2021

Published: 11 January 2022

Citation:

Sun Y, Qu Y and Zhao J (2022) The

Application of Tannic Acid

in Orthopedics.

Front. Mater. 8:801369.

doi: 10.3389/fmats.2021.801369

\section{The Application of Tannic Acid in Orthopedics}

\author{
Yingchuan Sun, Yang Qu and Jianwu Zhao* \\ Jilin University, Changchun, China
}

Tannic acid (TA) is a naturally occurring polyphenol compound commonly found in tea, wine, and fruits. Because of the excellent structural and functional properties afforded by TA, materials based on the structure of polyhydroxyphenols have great value, particularly for orthopedic transplantation. This compound, for example, can form a strong interaction with metals and can form a stable coating on their surfaces, thus, improving the physical and chemical properties of bone-implant surfaces and boosting implantation success rates. TA can also inhibit the activity of osteoclasts, thus, playing a potential role in the treatment of osteoporosis. Furthermore, if the body becomes polluted with heavy metals, TA can chelate the ions to protect bone morphology and structure. It also has a significant antibacterial effect and can reduce infections caused by surgical implantation and inhibit a variety of tumor cells, thereby promoting its potential application in spinal metastasis surgery. Furthermore, it can also slow the corrosion caused by magnesium alloys, thereby greatly improving the development of degradable orthopedic metal fixatives. Importantly, TA is cheap and easy to obtain, making it extremely valuable for use in orthopedics. This review focuses on the research status and practical applications of TA, and prospects for its future application for orthopedics (Figure 1).

Keywords: tannic acid, osteoporosis, antitumor, antibacterial, coating, heavy metal

\section{INTRODUCTION}

Tannic acid (TA) is a polyphenolic compound commonly found in many plants used for food and animal feed (Wang et al., 2020). Its empirical formula is represented by (Figure 2) $\mathrm{C}_{76} \mathrm{H}_{52} \mathrm{O}_{46}$ (Yan et al., 2020). The molecular structure of TA is composed of a central glucose unit, connected by 10 gallic acid molecules (Xu et al., 2018). TA is widely used for many diverse purposes, including industrial ink manufacture (when TA is mixed with ferric ions, a color reaction occurs), and is used for leather tanning, where it can bind to proteins (mainly collagen) through strong interactions, making them insoluble, more resistant to mechanical abrasion, and less susceptible to biodegradation (Chaplin, 1985; Belgacem and Gandini, 2008). Furthermore, this polyphenolic organic compound, possesses specific structural properties and biological activity, enabling it to be used as a building block for supramolecular assembly in the synthesis of biologically active nanomaterials (Lu et al., 2020). In the field of beauty and skin care, TA is widely added to cosmetics and skin care products to enhance their astringent, whitening, antiwrinkle, moisturizing, sun screening, antioxidant, and antiseptic effects (Ryeom et al., 2018; Chai et al., 2019). It also has important medical applications where it is often used to treat pharyngitis, tonsillitis, hemorrhoids, skin blisters, diarrhea, and intestinal bleeding (Li et al., 2018; Ren et al., 2019), and as an important lead-reducing compound, TA can also be used to inhibit Alzheimer's disease (Braidy et al., 2017). It is also important for the prevention and management of diabetes mellitus and its associated complications (Ajebli and 


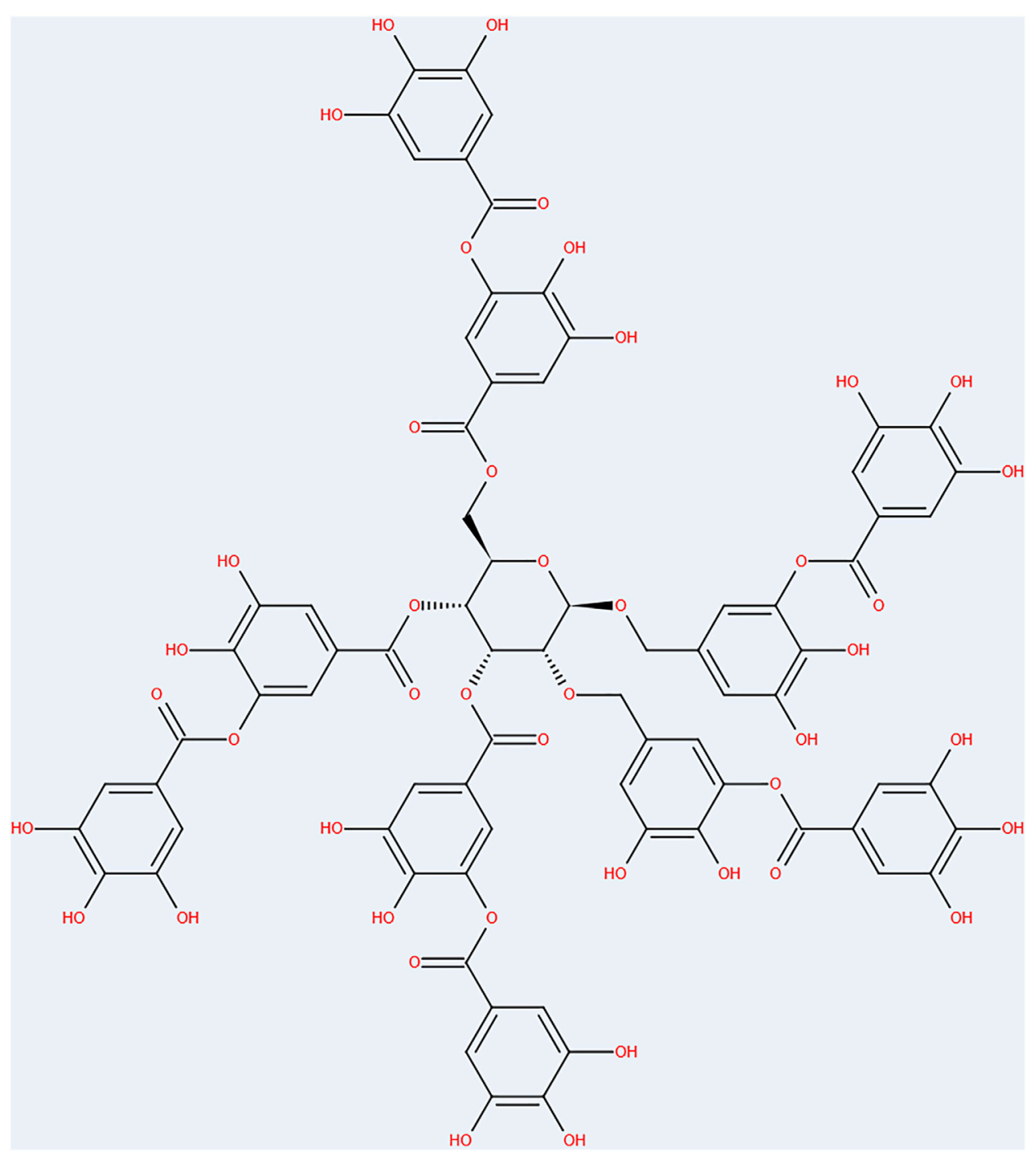

FIGURE 1 | The application of TA in orthopedics.

Eddouks, 2019). TA has a strong antibacterial function against Gram-positive and -negative bacteria when used as a coating, and shows good biocompatibility to mammalian cells (Sileika et al., 2013). As mentioned, TA can also scavenge reactive oxygen species and free radicals (Preedy, 2013) with anticancer and antimutagenic effects (King-Thom et al., 1998). In the field of orthopedic implants, TA can be crosslinked with a variety of metal implant surfaces and quickly coated on the metal surface (Ejima et al., 2013; Kim and Pasc, 2017) enabling better compatibility between the metals. As a plant polyphenol, TA represents a powerful synthetic tool for high-performance biocompatible bone adhesives, thereby avoiding the detrimental effects of traditional hydrogels, by enhancing water-resistant fixation, and guiding bone regeneration (Bai et al., 2020). In addition, the US Food and Drug Administration has classified $\mathrm{TA}$ as generally safe and relatively inexpensive, making it an ideal orthopedic material (Steffi et al., 2019a).

\section{TANNIC ACID ACTIVITY ON THE BONE-IMPLANT INTERFACE}

Orthopedic biomedical materials have the ability to repair or replace damaged bone and bone tissue during the treatment of orthopedic-related diseases and injuries, and help restore the normal physiological function of bones (Vogt et al., 2015). Currently, the application of biomedical materials in the field of orthopedics is becoming increasingly extensive and diversified. The physical and mechanical properties, as well as corrosion resistance and biocompatibility of various materials, have their own advantages. With increasing developmental and innovative 


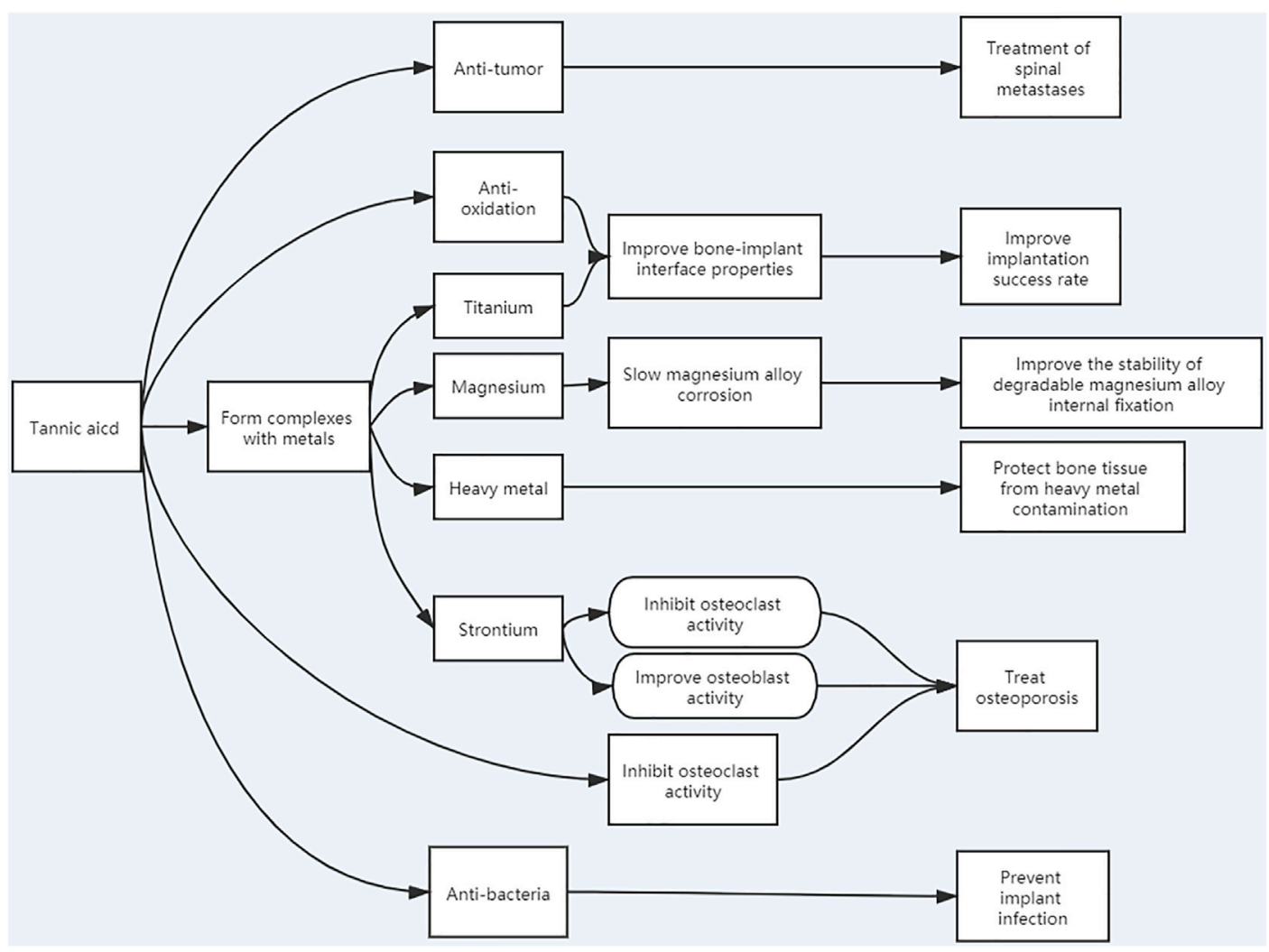

FIGURE 2 | The chemical structure of TA

advances in modern science and technology, higher expectations have been applied to the research and development of orthopedic biomedical materials (Gu et al., 2012; Guo et al., 2013). For example, the physical and chemical properties of the implant surface play a crucial role in the activity of bone cells at the bone-implant interface (Klymov et al., 2013). The oxidative stress generated by the accumulation of reactive oxygen species will hinder the osseointegration of the bone-implant interface (Chen et al., 2017). Oxidative stress can severely impair the biological function of osteoblasts, thereby hindering early bone formation and even cause implants to fail ( $\mathrm{Hu}$ et al., 2017). For example, titanium and its alloys are widely used in orthopedic implants where its excellent mechanical properties, ideal density, good corrosion resistance, and very low cytotoxicity are highly suited to a clinical application (Borsari et al., 2007; Chen et al., 2016). However, titanium and its alloys can form an inert oxide layer in the human body, thereby rendering the surface of the implant biologically inert, which is not conducive to the growth of new bone, and can result in poor osseointegration at the implant interface (Mei et al., 2014).

The polyphenolic hydroxyl group of TA has a strong ability to donate hydrogen atoms and, therefore, has a profound ability to eliminate oxygen free radicals (Marrassini et al., 2018). Therefore, TA is often used to improve the bone-implant interface. As an antioxidant compound, TA prevents lipid oxidation and free radical-mediated DNA cleavage caused by active oxygen scavenging and its derived free radicals, thus, inhibiting the formation of polycyclic aromatic hydrocarbondeoxyribonucleic acid adducts from in vivo or in vitro derived electrophiles and DNA (Khan et al., 2000; Baer-Dubowska and Szaefer, 2013). TA can also reduce the production of reactive oxygen species (ROS) by inhibiting the expression of NADPH oxidase-1 (NOX-1) (Xu et al., 2018). In addition, TA can increase serum levels of antioxidant enzymes, such as superoxide dismutase (SOD), catalase (CAT), glutathione (GSH), and endothelial nitric oxide synthase (e-NOS), which can remove tractive oxygen (Chu et al., 2016). Therefore, it can improve the physicochemical properties of the bone-implant interface, thus, improving the implantation efficiency and increasing its success rate. TA, therefore, has the potential to become a very suitable coating for orthopedic implants.

\section{THE APPLICATION OF TANNIC ACID IN OSTEOPOROSIS}

According to the 1994 definition by the World Health Organization (WHO), osteoporosis is a systemic bone disease characterized by low bone mass, bone microstructure damage, increased bone fragility, and susceptibility to fractures. The 
disease is also common in the elderly as approximately $40 \%$ of women and $14 \%$ of men over 50 years of age will develop osteoporosis-related fractures (Eastell and Lambert, 2002).

TA, as a polyphenol compound, can spontaneously adhere to the surface of various metal oxide substrates and form a thin coating through a metal-ligand interaction (Son et al., 2018). This effect helps to fix strontium onto the titanium surface, so that strontium, a metal ion is able to better promote osteoblast activity, with a concomitant inhibition of osteoclasts (Bonnelye et al., 2008; Steffi et al., 2019a). TA can also be complexed with calcium, where the calcium ions are fixed onto the surface of titanium dioxide nanotubes by forming a coordination complex with morpho TA, causing further phosphorylation to form an apatite coating, which can promote osteogenesis and long-lasting and effective antioxidant activity (Qiaoxia et al., 2020).

TA alone also has the ability to inhibit osteoclast activity which is important for homeostasis between osteoclast-mediated bone resorption and osteoblast-mediated bone formation. (Sims and Martin, 2020). Studies have shown that inhibition of osteoclast differentiation and function, and reduction of excessive osteoclast activation is an effective way to treat diseases of bone loss. (Hasegawa et al., 2019). TA can selectively affect mature osteoclasts by influencing receptor activator of NF-kB (RANK) and receptor activator of NF-kB ligand (RANKL) signaling, thereby reducing TRAP activity in osteoclasts (Park et al., 2004). Compared with pure titanium or titanium-dopamine complexes, titanium complexed with TA has been found to significantly reduce the total amount of DNA in osteoclasts and the number of actin rings, suggesting an inhibitory effect on activity and proliferation in these cells (Steffi et al., 2019b).

Therefore, surgery on patients with osteoporosis, especially osteoporotic fractures, is benefited by the combination of internal fixation and tannin, which cannot only produce a better fixation effect but also improve bone density and improve the success of the procedure, further reducing the frequency and probability of postoperative complications. Poly (methyl methacrylate) (PMMA), which is currently used to treat osteoporosis, has many disadvantages (high polymerization temperature, release of toxic monomers, poor histocompatibility, nonbiodegradable, nonosteoinductive, and can cause bone cement leakage, osteonecrosis in the vertebral body, and complications such as re-fracture of the vertebral body during surgery), making this compound far from ideal (Rho et al., 2012; Lv et al., 2015). Therefore, TA with its better performance may gradually replace PMMA as a frontline therapy, and its potential merits further exploration.

\section{THE PROTECTIVE EFFECT OF TANNIC ACID ON BONE DURING HEAVY METAL POLLUTION}

Cadmium and lead are highly toxic heavy metals that are widely present in the environment, having no current threshold limit for their toxic effects. Even if the concentration of these heavy metals found in the blood is only a few micrograms, they can still exert toxic effects (Winiarska-Mieczan, 2013). Due to their induction of oxidative stress, they can damage organs and exhibit mutagenic, genotoxic, carcinogenic, and teratogenic effects in both humans and animals (Bampidis et al., 2013). Lead mainly exists in the bone tissue in the body. Of all lead found in the body, $90 \%$ is found in the bone tissue (Cretacci and Parsons, 2010), and the two aforementioned metals can exist in the bones for more than 10 years and can replace the calcium in hydroxyapatite (Castelli et al., 2005). This mechanism can protect important organs and tissues from the direct impact of heavy metals, but long-term exposure to cadmium and lead can cause disorders of the nephron, increased calcium excretion, systemic osteomalacia, and osteoporosis, which are due to the competitive replacement of calcium ions from the bone tissue and a deterioration of the bone structure. This results in a reduction in the thickness of the bone trabecula, affecting their mechanical properties and causing frequent fractures (Agneta et al., 2006). Cadmium can also reduce body vitamin $\mathrm{D}$ content, reduce the absorption of calcium in the intestines, and cause bone deformation and softening (Brzóska et al., 2007).

TA contains multiple orthophenolic hydroxyl structures, which can be used as a multibase ligand to complex with metal ions. It has adjacent phenolic hydroxyl groups that can form a stable five-membered ring capable of chelating metal ions. Although the third phenolic hydroxyl group in the pyrogallol structure does not participate in this complex formation, it can promote the other two. Furthermore, the dissociation of phenolic hydroxyl groups can promote the formation and stability of complexes, thereby complexing with heavy metals such as lead and cadmium. For bone tissues that have been exposed to lead and cadmium, treatment with TA can increase the calcium content in the bone, increase trabecular bone density, increase trabecular bone volume to tissue volume ratio, increase the thickness of articular cartilage, and reduce the lead and cadmium content of the bone (Tomaszewska et al., 2017). Therefore, TA cannot only prevent bone damage caused by heavy metals in the early stage of heavy metal pollution but also can achieve better surgical results when used with internal fixation, in surgical treatments after bone injury, thereby improving bone quality and prognosis after surgery. TA can also be taken orally to remove any remaining heavy metal pollutants from the body and avoid further bone destruction.

\section{THE APPLICATION OF TANNIC ACID IN SPINAL METASTASES}

With continuous advances in medical technology, the survival period for cancer patients continues to grow, but metastasis of various tumors, including bone tumors, remains a serious problem and is increasing (Siegel et al., 2019). Approximately $60 \%$ of bone metastases occur in the spine (Bollen et al., 2018), $60 \%$ of all metastases occur in the bone tissue, and of this, $3 \%-30 \%$ occur in the spine (Siegel et al., 2018). Spinal metastases are often treated with surgery, especially if the general condition of the spine is poor, unstable, the tumor compresses the spinal cord, or the posterior column is 
TABLE 1 | The inhibitory effect of tannin on common spinal metastases.

\begin{tabular}{|c|c|c|c|}
\hline Primary disease & Proportion (\%) & Tannic acid inhibition & Reference \\
\hline Lung cancer & 32.25 & Cell cycle arrest & Sp et al., 2020 \\
\hline Breast cancer & 18.95 & $\begin{array}{l}\text { Inhibit epidermal growth factor receptor (EGFR) } \\
\text { Inhibit fatty acid synthase (Fas) }\end{array}$ & $\begin{array}{l}\text { Darvin et al., } 2017 \\
\text { Nie et al., } 2016\end{array}$ \\
\hline Gastrointestinal cancer & 15.72 & Inhibit Pyruvate kinase M2 (PKM2) & Yang et al., 2018 \\
\hline Prostate cancer & 6.54 & $\begin{array}{l}\text { Inhibit lipid metabolism pathway } \\
\text { Endoplasmic reticulum stress }\end{array}$ & $\begin{array}{l}\text { Nagesh et al., } 2018 \\
\text { Nagesh et al., } 2020\end{array}$ \\
\hline Thyroid cancer & 5.60 & - & - \\
\hline Hepatic carcinoma & 5.60 & Mediate oxidation & Mhlanga et al., 2019 \\
\hline Kidney cancer & 5.24 & - & - \\
\hline
\end{tabular}

invaded. In these circumstances, surgery is usually performed by way of simple percutaneous vertebroplasty (PVP), but when surgery is not possible, pedicle screw decompression techniques are often performed (Moussazadeh et al., 2015; Rajah et al., 2015). TA can inhibit the activity of DNA polymerase and telomerase in tumor cells and can inhibit cancer progression by inhibiting oxidative stress and reducing inflammatory damage (Majed et al., 2015; Savelyev et al., 2018). It can also inhibit the expression of cyclooxygenase-2 (COX-2) and the activation of nuclear factor-JB (NF-JB), and inhibit the overexpression of nitric oxide synthase (NOS), which contributes to the inhibition of tumor development (Majed et al., 2015). Treatment with TA also inhibits lung cancer cell viability through cell cycle arrest and can induce the intrinsic apoptosis pathway (Sp et al., 2020). It can also induce breast cancer cell apoptosis by affecting the cell epidermal growth factor receptor (EGFR) (Darvin et al., 2017) and as a natural fatty acid synthase (Fas) inhibitor to downregulate the expression of Fas in breast cancer cells and induce cancer cell apoptosis (Nie et al., 2016). TA can selectively inhibit the activity of an isoenzyme of glycolytic pyruvate kinase, M2 (PKM2), to cause inhibition of proliferation in gastrointestinal tumor cells (Yang et al., 2018). In prostate cancer cells, TA can inhibit signals for lipogenesis and the lipid metabolism pathway, and can mediate their apoptosis through the endoplasmic reticulum stress pathway (Nagesh et al., 2018; Nagesh et al., 2020). It can also induce caspase activation and increase the presence of ROS and reactive nitrogen species (RNS) in cells, while downregulating the expression of antioxidants, causing DNA breakage and increased death to liver cancer cells (Mhlanga et al., 2019). Compared with most traditional drug delivery systems, the combined technology of metal and TA ligands can improve the anticancer ability of drugs and achieve better therapeutic effects (Mathivanan et al., 2019). As a polyphenol, TA can form complexes with metals, thus, becoming a superior drug delivery system and improving the anticancer effect of nanomedicines and reducing the systemic toxicity of the drug (Ren et al., 2020). When tannins and internal fixation methods are used together, for example, the application of tannins combined with the pedicle screw technique, this hugely improves outcomes in surgery of spinal metastases (Table 1).

If TA is used as the coating for pedicle screws in spinal metastasis surgery, or in combination with bone cements to treat tumorinvaded vertebrae, this may help successful tumor resection and eliminate residual lesions. Due to its intrinsic anticancer properties,
TA may be beneficial for drug delivery to metastatic areas, thereby inhibiting the spread and recurrence of cancer.

\section{THE ROLE OF TANNIC ACID IN PREVENTING ORTHOPEDIC IMPLANT INFECTIONS}

In recent years, the number of orthopedic surgery procedures has continued to increase, but at the same time, cases of surgical failure are also on the rise. Among them, the failure of internal fixation caused by implant-related infections has led to a significant increase in the need for revision operations, and $45 \%$ of nosocomial infections after orthopedic surgery are caused by implant infections (Alvand et al., 2017). Due to the low blood supply on the surface of the implant and lack of nutrients, the bacterial biofilm produced tends to grow continuously and slowly, and drug resistance is often 1,000 times higher (Zoubos et al., 2012). The bacteria on the surface of orthopedic implants are composed of a variety of types, including Staphylococcus aureus, beta-hemolytic streptococcus, and aerobic Gram-negative bacilli (Getzlaf et al., 2016). Currently, 6-8 weeks of an anti-infective treatment (intravenous antibiotics) is adopted in clinical practice, but the shortcomings, such as difficulty to accurately manage the duration of use, low antibiotic concentration at the target site, and difficulty in achieving effective concentrations of drug at the surface of the implant, or in the biofilm, are all important confounding factors. Increasingly, medical practitioners have realized that relying solely on anti-infective treatment to prevent the occurrence of postoperative artificial implant infection is not ideal and is greatly limited (Schmidt et al., 2015; Song et al., 2015).

TA is a polydentate ligand, which binds to proteins mainly through hydrophobic interactions and hydrogen bonds, thereby inhibiting bacterial metabolism (Theisen et al., 2014; Jöbstl et al., 2006). Moreover, TA interacts with biomolecules and metal ions in bacteria to increase cell membrane permeability, disrupt cell membrane stability, and change the protein-to-lipid ratio, so that the assembled materials have good antibacterial properties (Chung et al., 1998). Importantly, due to its phenolic hydroxyl group, TA possesses antibacterial properties against specific bacteria, including $S$. aureus and E. coli (Dabbaghi et al., 2019), and can also be used as an inhibitor of the NorA efflux pump, producing antibacterial properties against Gram-positive bacteria, especially Glucococcus aureus and Enterococcus faecalis 
TABLE 2 | The resistance of tannins to the common pathogens of common orthopedic internal fixation infection.

\begin{tabular}{|c|c|c|}
\hline & $\begin{array}{l}\text { Common pathogens of } \\
\text { orthopedic implant infection } \\
\text { (Dabbaghi et al., 2019) }\end{array}$ & $\begin{array}{l}\text { Antibacterial properties of } \\
\text { tannic acid }\end{array}$ \\
\hline 1 & Staphylococcus aureus & Dabbaghi et al., 2019 (Schmidt et al., 2015) \\
\hline 2 & Staphylococcus epidermidis & Wang et al., 2018 (Belhaoues et al., 2020) \\
\hline 3 & Pseudomonas aeruginosa & Suzilla et al., 2020 (Pandey and Negi, 2018) \\
\hline 4 & Enterococcus faecalis & Belhaoues et al., 2020 (Song et al., 2015) \\
\hline 5 & Staphylococcus haemolyticus & - \\
\hline 6 & Escherichia coli & Pandey et al., 2018 (Theisen et al., 2014) \\
\hline
\end{tabular}

(Belhaoues et al., 2020). In higher concentrations, tannins can also inhibit the intake of sugars and amino acids, thereby inhibiting bacterial growth (Pandey and Negi, 2018). TA can exert its antibacterial effect by inhibiting the biofilm formation of G. aureus, Streptococcus, Streptococcus mutans, and others (Lee et al., 2013; Dong et al., 2018) (Table 2). Interestingly, TA can also reduce $\mathrm{Ag}^{+}$to $\mathrm{Ag}$ nanoparticles in situ, thereby promoting a synergistic antibacterial effect between them (Lu et al., 2020). Moreover, TA can combine with several cationic antibiotics (tobramycin, gentamicin, and polymyxin B) to form a highly efficient, bioresponsive, and controlled-release antibacterial coating, which can be used to prevent bacterial colonization of biomedical devices (Zhuk et al., 2014).

An ideal orthopedic implant material, therefore, should not only have the ability to resist infection, but also be able to promote fracture healing. These two prerequisites, however, are difficult to fulfill at the same time. If TA is used as a coating, it can be used in combination with metal implants to take advantage of its affinity with metal, promote bone formation, and enhanced antibacterial effects (Yang et al., 2019).

\section{TANNIC ACID CAN IMPROVE THE CORROSION RESISTANCE OF MAGNESIUM ALLOY INTERNAL FIXATION}

In medicine, metallic materials have been widely used due to their high mechanical strength, toughness, and good machining performance. However, alloy materials cannot be degraded in the body, and most of them need to be removed by a second operation, causing socioeconomic burden, and pain caused by this secondary procedure (Hermawan, 2018). However, degradable internal fixation materials are well capable of solving these existing problems. From research, looking at new biodegradable metallic materials, magnesium and magnesium alloys have become a more important research option due to their nontoxicity and superior mechanical properties (Li et al., 2008). However, the rapid corrosion rate of magnesium alloys in the human environment has become a bottleneck for further development. Controlling the degradation rate of magnesium alloys, therefore, represents a large gap in the field of medical devices that needs to be overcome (Sezer et al., 2018).

TA can be used as a polymetallic ligand to react with metal ions to form a metal-tannin complex due to its polyphenol structure with hydroxyl groups in the ortho position. Because polyphenol hydroxyl groups are negatively charged at physiological $\mathrm{pH}, \mathrm{TA}$ is expected to be able to achieve supramolecular assembly by electrostatic interaction with cationic compounds (Abouelmagd et al., 2019). The two ortho-hydroxy groups in the form of oxygen anions can react with metal ions to form a chelate and avoid metal corrosion (Gust and Suwalski, 1994). Therefore, TA can form a dense and stable conversion film on metallic surfaces, thus exhibiting good resistance to corrosion (Chen et al., 2009). TA can also be hydrolyzed and then react with $\mathrm{Mg}^{2+}$ ions to form magnesium hydroxybenzoate, further preventing corrosion to magnesium alloys (Chen et al., 2008). In addition, this TA coating can improve the biocompatibility of magnesium alloys while protecting the magnesium alloys from corrosion, highlighting a bright future for its use with degradable magnesium alloys (Zhu et al., 2017). If research in this area can be improved further, it will greatly complement the shortcomings seen with degradable magnesium alloy internal fixation materials, thus, promoting its development and optimization may result in a new era for orthopedic surgery.

\section{CHALLENGES}

Although it has a wide range of application prospects and great application value, TA and its research and progress in the field of orthopedics still face many challenges. TA can inhibit the absorption of iron of the body (Montanaro et al., 2011), thereby causing anemia, which will adversely affect the recovery of patients after orthopedic surgery. However, this study mostly focused on the intake of TA as food, whether it will cause anemia after being degraded in the body as a coating or hydrogel still needs us to continue to explore. Yet, clinical applications of TA have been limited owing to its poor lipid solubility, low bioavailability, and short half-life (Wang et al., 2018). How to overcome the above problems so that TA can be used in orthopedics clinics as soon as possible is also our direction of effort.

\section{CONCLUSION}

Orthopedic diseases are diverse, and their treatment requires the development of new biomaterials and drugs to achieve better 
therapeutic effects. Many studies in recent years have found that the application of TA in the field of orthopedics has unlimited potential and bright prospects. TA possesses many beneficial biological effects including antioxidation, antibacterial, and osteogenic effects, and is an ideal material for coating orthopedic implants. Its unique antiosteoclast property makes it a potential treatment for elderly patients with osteoporosis, and its surface and osteoclast inhibitory properties make it a potential replacement for bone cement as a new material for assisting internal fixation for patients with osteoporosis. Furthermore, the protective effect of TA on bone tissue after heavy metal infection makes it useful for patients with poor bone quality after heavy metal pollution. In addition, a series of reports also found promising results for $\mathrm{TA}$ as an antitumor agent, suggesting a

\section{REFERENCES}

Abouelmagd, S. A., Abd Ellah, N. H., Amen, O., Abdelmoez, A., and Mohamed, N. G. (2019). Self-assembled Tannic Acid Complexes for pH-Responsive Delivery of Antibiotics: Role of Drug-Carrier Interactions. Int. J. pharmaceutics 562, 76-85. doi:10.1016/j.ijpharm.2019.03.009

Agneta, Å, Per, B., Thomas, L., Lidfeldt, J., Nerbrand, C., Samsioe, G., et al. (2006). Cadmium-Induced Effects on Bone in a Population-Based Study of Women. Environ. Health Perspect. 114 (6), 830-834. doi:10.1289/ehp.8763

Ajebli, M., and Eddouks, M. (2019). The Promising Role of Plant Tannins as Bioactive Antidiabetic Agents. Curr. Med. Chem. 26 (25), 4852-4884. doi:10.2174/0929867325666180605124256

Alvand, A., Rezapoor, M., and Parvizi, J. (2017). The Role of Biomarkers for the Diagnosis of Implant-Related Infections in Orthopaedics and Trauma. Adv. Exp. Med. Biol. 971, 69-79. doi:10.1007/5584_2017_11

Baer-Dubowska, W., and Szaefer, H. (2013). Modulation of CarcinogenMetabolizing Cytochromes $\mathrm{P} 450$ by Phytochemicals in Humans. Expert Opin. Drug Metab. Toxicol. 9 (8), 927-941. doi:10.1517/ 17425255.2013.795219

Bai, S., Zhang, X., Lv, X., Zhang, M., Huang, X., Shi, Y., et al. (2020). Bioinspired Mineral-Organic Bone Adhesives for Stable Fracture Fixation and Accelerated Bone Regeneration. Adv. Funct. Mater. 30 (5), 1908381. doi:10.1002/ adfm.201908381

Bampidis, V. A., Nistor, E., and Nitas, D. (2013). Arsenic, Cadmium, Lead and Mercury as Undesirable Substances in Animal Feeds. Scientific Pap. Anim. Sci. Biotechnologies/Lucrari Stiintifice: Zootehnie si Biotehnologii 46 (1), 17-22.

Belgacem, M. N., and Gandini, A. (2008). Monomers, Polymers and Composites from Renewable Resources. ScienceDirect.

Belhaoues, S., Amri, S., and Bensouilah, M. (2020). Major Phenolic Compounds, Antioxidant and Antibacterial Activities of Anthemis Praecox Link Aerial Parts. South Afr. J. Bot. 131, 200-205. doi:10.1016/j.sajb.2020.02.018

Bollen, L., Dijkstra, S., Bartels, R., de Graeff, A., Poelma, D. L. H., Brouwer, T., et al. (2018). Clinical Management of Spinal Metastases-The Dutch National Guideline. Eur. J. Cancer 104, 81-90. doi:10.1016/j.ejca.2018.08.028

Bonnelye, E., Chabadel, A., Saltel, F., and Jurdic, P. (2008). Dual Effect of Strontium Ranelate: Stimulation of Osteoblast Differentiation and Inhibition of Osteoclast Formation and Resorption In Vitro. Bone 42 (1), 129-138. doi:10.1016/ j.bone.2007.08.043

Borsari, V., Fini, M., Giavaresi, G., Rimondini, L., Consolo, U., Chiusoli, L., et al. (2007). Osteointegration of Titanium and Hydroxyapatite Rough Surfaces in Healthy and Compromised Cortical and Trabecular Bone: In Vivo Comparative Study on Young, Aged, and Estrogen-Deficient Sheep. J. Orthop. Res. 25 (9), 1250-1260. doi:10.1002/jor.20413

Braidy, N., Jugder, B. E., Poljak, A., Jayasena, T., Nabavi, S. M., Sachdev, P., et al. (2017). Molecular Targets of Tannic Acid in Alzheimer's Disease. Curr. Alzheimer Res. 14 (8), 861-869. doi:10.2174/1567205014666170206163158

Brzóska, M. M., Rogalska, J., Galażyn-Sidorczuk, M., Jurczuk, M., Roszczenko, A., Kulikowska-Karpińska, E., et al. (2007). Effect of Zinc Supplementation on role in spinal metastasis and even primary tumors. This effect has not been fully investigated yet, but does represent a promising new area of research for the future. As a material with both good coating performance and corrosion resistance, TA is likely to become a boost for the advancement of orthopedic biodegradable internal fixation materials, and it is believed that with continuous in-depth development and research, its value to transplantation orthopedics will be soon realized (Suzilla et al., 2020).

\section{AUTHOR CONTRIBUTIONS}

YS wrote the article. YQ proposed the ideas. JZ reviewed the article.

Bone Metabolism in Male Rats Chronically Exposed to Cadmium. Toxicology 237, 89-103. doi:10.1016/j.tox.2007.05.001

Castelli, M., Rossi, B., Corsetti, F., Mantovani, A., Spera, G., Lubrano, C., et al. (2005). Levels of Cadmium and lead in Blood: an Application of Validated Methods in a Group of Patients with Endocrine/metabolic Disorders from the Rome Area. Microchemical J. 79 (1-2), 349-355. doi:10.1016/ j.microc.2004.05.003

Chai, W.-M., Wei, Q.-M., Deng, W.-L., Zheng, Y.-L., Chen, X.-Y., Huang, Q., et al. (2019). Anti-melanogenesis Properties of Condensed Tannins from Vigna Angularis Seeds with Potent Antioxidant and DNA Damage protection Activities. Food Funct. 10 (1), 99-111. doi:10.1039/c8fo01979g

Chaplin, A. J. (1985). Tannic Acid in Histology: an Historical Perspective. Stain Technol. 60 (4), 219-231. doi:10.3109/10520298509113916

Chen, J., Zhang, X., Cai, H., Chen, Z., Wang, T., Jia, L., et al. (2016). Osteogenic Activity and Antibacterial Effect of Zinc Oxide/carboxylated Graphene Oxide Nanocomposites: Preparation and In Vitro Evaluation. Colloids Surf. B: Biointerfaces 147, 397-407. doi:10.1016/j.colsurfb.2016.08.023

Chen, W., Shen, X., Hu, Y., Xu, K., Ran, Q., Yu, Y., et al. (2017). Surface Functionalization of Titanium Implants with Chitosan-Catechol Conjugate for Suppression of ROS-Induced Cells Damage and Improvement of Osteogenesis. Biomaterials 114, 82-96. doi:10.1016/ j.biomaterials.2016.10.055

Chen, X., Li, G., Lian, J., and Jiang, Q. (2008). An Organic Chromium-free Conversion Coating on AZ91D Magnesium alloy. Appl. Surf. Sci. 255, 2322-2328. doi:10.1016/j.apsusc.2008.07.092

Chen, X., Li, G., Lian, J., and Jiang, Q. (2009). Study of the Formation and Growth of Tannic Acid Based Conversion Coating on AZ91D Magnesium alloy. Surf. Coat. Tech. 204 (5), 736-747. doi:10.1016/j.surfcoat.2009.09.022

Chu, X., Wang, H., Jiang, Y.-m., Zhang, Y.-y., Bao, Y.-f., Zhang, X., et al. (2016). Ameliorative Effects of Tannic Acid on Carbon Tetrachloride-Induced Liver Fibrosis In Vivo and In Vitro. J. Pharmacol. Sci. 130 (1), 15-23. doi:10.1016/ j.jphs.2015.12.002

Chung, K.-T., Lu, Z., and Chou, M. W. (1998). Mechanism of Inhibition of Tannic Acid and Related Compounds on the Growth of Intestinal Bacteria. Food Chem. Toxicol. 36 (12), 1053-1060. doi:10.1016/s0278-6915(98)00086-6

Cretacci, Y., and Parsons, P. J. (2010). Localized Accumulation of lead within and Among Bones from lead-dosed Goats. Environ. Res. 110 (1), 26-32. doi:10.1016/j.envres.2009.09.005

Dabbaghi, A., Kabiri, K., Ramazani, A., Zohuriaan-Mehr, M. J., and Jahandideh, A. (2019). Synthesis of Bio-based Internal and External Cross-linkers Based on Tannic Acid for Preparation of Antibacterial Superabsorbents. Polym. Adv. Technol. 30 (11), 2894-2905. doi:10.1002/pat.4722

Darvin, P., Joung, Y. H., Kang, D. Y., Sp, N., Byun, H. J., Hwang, T. S., et al. (2017). Tannic Acid Inhibits EGFR/STAT1/3 and Enhances p38/STAT1 Signalling axis in Breast Cancer Cells. J. Cel. Mol. Med. 21 (4), 720-734. doi:10.1111/ jcmm.13015

Dong, G., Liu, H., Yu, X., Zhang, X., Lu, H., Zhou, T., et al. (2018). Antimicrobial and Anti-biofilm Activity of Tannic Acid against Staphylococcus aureus. Nat. Prod. Res. 32 (18), 2225-2228. doi:10.1080/14786419.2017.1366485 
Eastell, R., and Lambert, H. (2002). Plenary Lecture: Strategies for Skeletal Health in the Elderly. Proc. Nutr. Soc. 61 (2), 173-180. doi:10.1079/pns2002160

Ejima, H., Richardson, J. J., Liang, K., Best, J. P., van Koeverden, M. P., Such, G. K., et al. (2013). One-step Assembly of Coordination Complexes for Versatile Film and Particle Engineering. Science 341 (6142), 154-157. doi:10.1126/ science. 1237265

Getzlaf, M. A., Lewallen, E. A., Kremers, H. M., Jones, D. L., Bonin, C. A., Dudakovic, A., et al. (2016). Multi-disciplinary Antimicrobial Strategies for Improving Orthopaedic Implants to Prevent Prosthetic Joint Infections in Hip and Knee. J. Orthop. Res. 34 (2), 177-186. doi:10.1002/jor.23068

Gu, X. N., Xie, X. H., Li, N., Zheng, Y. F., and Qin, L. (2012). In Vitro and In Vivo Studies on a Mg-Sr Binary alloy System Developed as a New Kind of Biodegradable Metal. Acta Biomater. 8 (6), 2360-2374. doi:10.1016/ j.actbio.2012.02.018

Guo, Y., Ren, L., Liu, C., Yuan, Y., Lin, X., Tan, L., et al. (2013). Effect of Implantation of Biodegradable Magnesium alloy on BMP-2 Expression in Bone of Ovariectomized Osteoporosis Rats. Mater. Sci. Eng. C 33 (7), 4470-4474. doi:10.1016/j.msec.2013.05.042

Gust, J., and Suwalski, J. (1994). Use of Mössbauer Spectroscopy to Study Reaction Products of Polyphenols and Iron Compounds. Corrosion 50 (5), 355-365. doi:10.5006/1.3294344

Hasegawa, T., Kikuta, J., Sudo, T., Matsuura, Y., Matsui, T., Simmons, S., et al. (2019). Identification of a Novel Arthritis-Associated Osteoclast Precursor Macrophage Regulated by FoxM1. Nat. Immunol. 20 (12), 1631-1643. doi:10.1038/s41590-019-0526-7

Hermawan, H. (2018). Updates on the Research and Development of Absorbable Metals for Biomedical Applications. Prog. Biomater. 7 (2), 93-110. doi:10.1007/ s40204-018-0091-4

Hu, X.-F., Wang, L., Lu, Y.-Z., Xiang, G., Wu, Z.-X., Yan, Y.-B., et al. (2017). Adiponectin Improves the Osteointegration of Titanium Implant under Diabetic Conditions by Reversing Mitochondrial Dysfunction via the AMPK Pathway In Vivo and In Vitro. Acta Biomater. 61, 233-248. doi:10.1016/ j.actbio.2017.06.020

Jöbstl, E., Howse, J. R., Fairclough, J. P. A., and Williamson, M. P. (2006). Noncovalent Cross-Linking of Casein by Epigallocatechin Gallate Characterized by Single Molecule Force Microscopy. J. Agric. Food Chem. 54 (12), 4077-4081. doi:10.1021/jf053259f

Khan, N. S., Ahmad, A., and Hadi, S. M. (2000). Anti-oxidant, Pro-oxidant Properties of Tannic Acid and its Binding to DNA. Chemico-biological interactions 125 (3), 177-189. doi:10.1016/s0009-2797(00)00143-5

Kim, S., and Pasc, A. (2017). Advances in Multifunctional Surface Coating Using Metal-Phenolic Networks. Bull. Korean Chem. Soc. 38 (5), 519-520. doi:10.1002/bkcs.11123

King-Thom, C., Tit Yee, W., Cheng, I. W., Yao-Wen, H., and Yuan, L. (1998). Tannins and Human Health: A Review. Crit. Rev. Food Sci. Nutr. 38 (6), 421-464. doi:10.1080/10408699891274273

Klymov, A., Prodanov, L., Lamers, E., Jansen, J. A., and Walboomers, X. F. (2013). Understanding the Role of Nano-Topography on the Surface of a BoneImplant. Biomater. Sci. 1 (2), 135-151. doi:10.1039/c2bm00032f

Lee, J.-H., Park, J.-H., Cho, H. S., Joo, S. W., Cho, M. H., and Lee, J. (2013). Antibiofilm Activities of Quercetin and Tannic Acid againstStaphylococcus Aureus. Biofouling 29 (5), 491-499. doi:10.1080/08927014.2013.788692

Li, N., Yang, X., Liu, W., Xi, G., Wang, M., Liang, B., et al. (2018). Tannic Acid Cross-Linked Polysaccharide-Based Multifunctional Hemostatic Microparticles for the Regulation of Rapid Wound Healing. Macromol Biosci. 18 (11), e1800209. doi:10.1002/mabi.201800209

Li, Z., Gu, X., Lou, S., and Zheng, Y. (2008). The Development of Binary Mg-Ca Alloys for Use as Biodegradable Materials within Bone. Biomaterials 29 (10), 1329-1344. doi:10.1016/j.biomaterials.2007.12.021

Lu, R., Zhang, X., Cheng, X., Zhang, Y., Zan, X., and Zhang, L. (2020). Medical Applications Based on Supramolecular Self-Assembled Materials from Tannic Acid. Front. Chem. 8, 583484. doi:10.3389/fchem.2020.583484

Lv, Y., Li, A., Zhou, F., Pan, X., Liang, F., Qu, X., et al. (2015). A Novel Composite PMMA-Based Bone Cement with Reduced Potential for Thermal Necrosis. ACS Appl. Mater. Inter. 7 (21), 11280-11285. doi:10.1021/acsami.5b01447

Majed, F., Rashid, S., Khan, A. Q., Nafees, S., Ali, N., Ali, R., et al. (2015). Tannic Acid Mitigates the DMBA/croton Oil-Induced Skin Cancer Progression in Mice. Mol. Cel Biochem 399, 217-228. doi:10.1007/s11010-014-2248-3
Marrassini, C., Peralta, I., and Anesini, C. (2018). Comparative Study of the Polyphenol Content-Related Anti-inflammatory and Antioxidant Activities of Two Urera Aurantiaca Specimens from Different Geographical Areas. Chin. Med. 13, 22. doi:10.1186/s13020-018-0181-1

Mathivanan, N., Paramasivam, G., Vergaelen, M., Rajendran, J., Hoogenboom, R., and Sundaramurthy, A. (2019). Hydrogen-Bonded Multilayer Thin Films and Capsules Based on Poly(2-N-Propyl-2-Oxazoline) and Tannic Acid: Investigation on Intermolecular Forces, Stability, and Permeability. Langmuir 35 (45), 14712-14724. doi:10.1021/acs.langmuir.9b02938

Mei, S., Wang, H., Wang, W., Tong, L., Pan, H., Ruan, C., et al. (2014). Antibacterial Effects and Biocompatibility of Titanium Surfaces with Graded Silver Incorporation in Titania Nanotubes. Biomaterials 35 (14), 4255-4265. doi:10.1016/j.biomaterials.2014.02.005

Mhlanga, P., Perumal, P. O., Somboro, A. M., Amoako, D. G., Khumalo, H. M., and Khan, R. B. (2019). Mechanistic Insights into Oxidative Stress and Apoptosis Mediated by Tannic Acid in Human Liver Hepatocellular Carcinoma Cells. Int. J. Mol. Sci. 20 (24), 6145. doi:10.3390/ijms 20246145

Montanaro, L., Speziale, P., Campoccia, D., Ravaioli, S., Cangini, I., Pietrocola, G., et al. (2011). Scenery of Staphylococcus Implant Infections in Orthopedics. Future Microbiol. 6 (11), 1329-1349. doi:10.2217/fmb.11.117

Moussazadeh, N., Rubin, D. G., McLaughlin, L., Lis, E., Bilsky, M. H., and Laufer, I. (2015). Short-segment Percutaneous Pedicle Screw Fixation with Cement Augmentation for Tumor-Induced Spinal Instability. Spine J. 15 (7), 1609-1617. doi:10.1016/j.spinee.2015.03.037

Nagesh, P. K. B., Hatami, E., Chowdhury, P., Kashyap, V. K., Khan, S., Hafeez, B. B., et al. (2018). Tannic Acid Induces Endoplasmic Reticulum Stress-Mediated Apoptosis in Prostate Cancer. Cancers (Basel) 10 (3), 68. doi:10.3390/ cancers 10030068

Nagesh, P. K. B., Chowdhury, P., Hatami, E., Jain, S., Dan, N., Kashyap, V. K., et al. (2020). Tannic Acid Inhibits Lipid Metabolism and Induce ROS in Prostate Cancer Cells. Sci. Rep. 10 (1), 980. doi:10.1038/s41598-020-57932-9

Nie, F., Liang, Y., Jiang, B., Li, X., Xun, H., He, W., et al. (2016). Apoptotic Effect of Tannic Acid on Fatty Acid Synthase Over-expressed Human Breast Cancer Cells. Tumor Biol. 37 (2), 2137-2143. doi:10.1007/s13277-015-4020-z

Pandey, A., and Negi, P. S. (2018). Phytochemical Composition, In Vitro Antioxidant Activity and Antibacterial Mechanisms of Neolamarckia Cadamba Fruits Extracts. Nat. Prod. Res. 32 (10), 1189-1192. doi:10.1080/ 14786419.2017.1323209

Park, E. K., Kim, M. S., Lee, S. H., Kim, K. H., Park, J.-Y., Kim, T.-H., et al. (2004). Furosin, an Ellagitannin, Suppresses RANKL-Induced Osteoclast Differentiation and Function through Inhibition of MAP Kinase Activation and Actin Ring Formation. Biochem. Biophysical Res. Commun. 325 (4), 1472-1480. doi:10.1016/j.bbrc.2004.10.197

Preedy, V. (2013). Tea in Health and Disease Prevention. ScienceDirect.

Qiaoxia, L., Yujie, Z., Meng, Y., Yizhu, C., Yan, W., Yinchun, H., et al. (2020). Hydroxyapatite/tannic Acid Composite Coating Formation Based on Ti Modified by TiO2 Nanotubes. Colloids Surf. B: Biointerfaces 196, 111304. doi:10.1016/j.colsurfb.2020.111304

Rajah, G., Altshuler, D., Sadiq, O., Nyame, V. K., Eltahawy, H., and Szerlip, N. (2015). Predictors of Delayed Failure of Structural Kyphoplasty for Pathological Compression Fractures in Cancer Patients. J. Neurosurg. Spine 23 (2), 228-232. doi:10.3171/2014.11.spine14909

Ren, Y., Li, X., Han, B., Zhao, N., Mu, M., Wang, C., et al. (2019). Improved Anticolorectal Carcinomatosis Effect of Tannic Acid Co-loaded with Oxaliplatin in Nanoparticles Encapsulated in Thermosensitive Hydrogel. Eur. J. Pharm. Sci. 128, 279-289. doi:10.1016/j.ejps.2018.12.007

Ren, Z., Sun, S., Sun, R., Cui, G., Hong, L., Rao, B., et al. (2020). A MetalPolyphenol-Coordinated Nanomedicine for Synergistic Cascade Cancer Chemotherapy and Chemodynamic Therapy. Adv. Mater. 32 (6), e1906024. doi:10.1002/adma.201906024

Rho, Y.-J., Choe, W. J., and Chun, Y. I. (2012). Risk Factors Predicting the New Symptomatic Vertebral Compression Fractures after Percutaneous Vertebroplasty or Kyphoplasty. Eur. Spine Jofficial Publication Eur. Spine Soc. Eur. Spinal Deformity Societyand Eur. Section Cervical Spine Res. Soc. 21 (5), 905-911. doi:10.1007/s00586-011-2099-5

Ryeom, G. G. M., Bang, W. J., Kim, Y. B., and Lee, G. E. (2018). Gallotannin Improves the Photoaged-Related Proteins by Extracellular SignalRegulated Kinases/c-Jun N-Terminal Kinases Signaling Pathway in 
Human Epidermal Keratinocyte Cells. J. Med. Food 21 (8), 785-792. doi:10.1089/jmf.2017.4096

Savelyev, N., Baykuzina, P., Dokudovskaya, S., Lavrik, O., Rubtsova, M., and Dontsova, O. (2018). Comprehensive Analysis of Telomerase Inhibition by Gallotannin. Oncotarget 9 (27), 18712-18719. doi:10.18632/oncotarget.24642

Schmidt, A., Bénard, S., and Cyr, S. (2015). Hospital Cost of Staphylococcal Infection after Cardiothoracic or Orthopedic Operations in France: A Retrospective Database Analysis. Surg. infections 16 (4), 428-435. doi:10.1089/sur.2014.045

Sezer, N., Evis, Z., Kayhan, S. M., Tahmasebifar, A., and Koç, M. (2018). Review of Magnesium-Based Biomaterials and Their Applications. J. Magnesium Alloys 6 (1), 23-43. doi:10.1016/j.jma.2018.02.003

Siegel, R. L., Miller, K. D., and Jemal, A. (2018). Cancer Statistics, 2018. CA: a Cancer J. clinicians 68 (1), 7-30. doi:10.3322/caac.21442

Siegel, R. L., Miller, K. D., and Jemal, A. (2019). Cancer Statistics, 2019. CA A. Cancer J. Clin. 69 (1), 7-34. doi:10.3322/caac.21551

Sileika, T. S., Barrett, D. G., Zhang, R., Lau, K. H. A., and Messersmith, P. B. (2013). Colorless Multifunctional Coatings Inspired by Polyphenols Found in tea, Chocolate, and Wine. Angew. Chem. Int. Ed. 52 (41), 10766-10770. doi:10.1002/anie.201304922

Sims, N. A., and Martin, T. J. (2020). Osteoclasts Provide Coupling Signals to Osteoblast Lineage Cells through Multiple Mechanisms. Annu. Rev. Physiol. 82, 507-529. doi:10.1146/annurev-physiol-021119-034425

Son, H. Y., Jun, H., Kim, K. R., Hong, C. A., and Nam, Y. S. (2018). Tanninmediated Assembly of Gold-Titanium Oxide Hybrid Nanoparticles for Plasmonic Photochemical Applications. J. Ind. Eng. Chem. 63, 420-425. doi:10.1016/j.jiec.2018.03.002

Song, W. C., Zhang, S. S., and Gong, Y. H. (2015). Distribution and Drug Resistance Profile of Methicillin-Resistant Staphylococcus aureus after Orthopaedic Surgery. Pak J. Pharm. Sci. 28 (3 Suppl. 1), 1151-1154.

Sp, N., Kang, D. Y., Kim, D. H., Yoo, J.-S., Jo, E. S., Rugamba, A., et al. (2020). Tannic Acid Inhibits Non-small Cell Lung Cancer (NSCLC) Stemness by Inducing G0/G1 Cell Cycle Arrest and Intrinsic Apoptosis. Anticancer Res. 40 (6), 3209-3220. doi:10.21873/anticanres.14302

Steffi, C., Shi, Z., Kong, C. H., Chong, S. W., Wang, D., and Wang, W. (2019). Use of Polyphenol Tannic Acid to Functionalize Titanium with Strontium for Enhancement of Osteoblast Differentiation and Reduction of Osteoclast Activity. Polymers (Basel) 11, 1256. doi:10.3390/polym11081256

Steffi, C., Shi, Z., Kong, C. H., and Wang, W. (2019). Bioinspired Polydopamine and Polyphenol Tannic Acid Functionalized Titanium Suppress Osteoclast Differentiation: a Facile and Efficient Strategy to Regulate Osteoclast Activity at Bone-Implant Interface. J. R. Soc. Interf. 16 (152), 20180799. doi:10.1098/rsif.2018.0799

Suzilla, W. Y., Izzati, A., Isha, I., Zalina, A., and Rajaletchumy, V. K. (2020). Formulation and Evaluation of Antimicrobial Herbosomal Gel from Quercus Infectoria Extract. IOP Conf. Ser. Mater. Sci. Eng. 736, 022030, 2020 . Paper presented at:. doi:10.1088/1757-899x/736/2/022030

Theisen, L. L., Erdelmeier, C. A. J., Spoden, G. A., Boukhallouk, F., Sausy, A., Florin, L., et al. (2014). Tannins from Hamamelis Virginiana Bark Extract: Characterization and Improvement of the Antiviral Efficacy against Influenza A Virus and Human Papillomavirus. PloS one 9 (1), e88062. doi:10.1371/journal.pone.0088062

Tomaszewska, E., Dobrowolski, P., Winiarska-Mieczan, A., Kwiecień, M., Tomczyk, A., and Muszyński, S. (2017). The Effect of Tannic Acid on the
Bone Tissue of Adult Male Wistar Rats Exposed to Cadmium and lead. Exp. Toxicologic Pathol. 69 (3), 131-141. doi:10.1016/j.etp.2016.12.003

Vogt, S., Tischer, T., and Blanke, F. (2015). Biomaterialien in der Orthopädie. Orthopäde 44 (8), 649-660. doi:10.1007/s00132-015-3147-3

Wang, C., Zhou, H., Niu, H., Ma, X., Yuan, Y., Hong, H., et al. (2018). Tannic AcidLoaded Mesoporous Silica for Rapid Hemostasis and Antibacterial Activity. Biomater. Sci. 6 (12), 3318-3331. doi:10.1039/c8bm00837j

Wang, Z., Li, S., Ge, S., and Lin, S. (2020). Review of Distribution, Extraction Methods, and Health Benefits of Bound Phenolics in Food Plants. J. Agric. Food Chem. 68 (11), 3330-3343. doi:10.1021/acs.jafc.9b06574

Winiarska-Mieczan, A. (2013). Protective Effect of Tannic Acid on the Brain of Adult Rats Exposed to Cadmium and lead. Environ. Toxicol. Pharmacol. 36 (1), 9-18. doi:10.1016/j.etap.2013.02.018

Xu, Y., Hu, M., Chen, S., Chen, F., Wang, C., Tang, Y., et al. (2018). Tannic Acid Attenuated Irradiation-Induced Apoptosis in Megakaryocytes. Exp. Cel Res. 370 (2), 409-416. doi:10.1016/j.yexcr.2018.07.003

Yan, W., Shi, M., Dong, C., Liu, L., and Gao, C. (2020). Applications of Tannic Acid in Membrane Technologies: A Review. Adv. Colloid Interf. Sci. 284, 102267. doi:10.1016/j.cis.2020.102267

Yang, P., Ding, G.-B., Liu, W., Fu, R., Sajid, A., and Li, Z. (2018). Tannic Acid Directly Targets Pyruvate Kinase Isoenzyme M2 to Attenuate colon Cancer Cell Proliferation. Food Funct. 9 (11), 5547-5559. doi:10.1039/c8fo01161c

Yang, S., Wang, Y., Wu, X., Sheng, S., Wang, T., and Zan, X. (2019). Multifunctional Tannic Acid (TA) and Lysozyme (Lys) Films Built Layer by Layer for Potential Application on Implant Coating. ACS Biomater. Sci. Eng. 5 (7), 3582-3594. doi:10.1021/acsbiomaterials.9b00717

Zhu, B., Wang, S., Wang, L., Yang, Y., Liang, J., and Cao, B. (2017). Preparation of Hydroxyapatite/Tannic Acid Coating to Enhance the Corrosion Resistance and Cytocompatibility of AZ31 Magnesium Alloys. Coatings 7 (7), 105. doi:10.3390/ coatings 7070105

Zhuk, I., Jariwala, F., Attygalle, A. B., Wu, Y., Libera, M. R., and Sukhishvili, S. A. (2014). Self-defensive Layer-By-Layer Films with Bacteria-Triggered Antibiotic Release. ACS nano 8 (8), 7733-7745. doi:10.1021/nn500674g

Zoubos, A. B., Galanakos, S. P., and Soucacos, P. N. (2012). Orthopedics and Biofilm-Wwhat Do We Know? A Review. Med. Sci. Monit. 18 (6), Ra89-96. doi: $10.12659 / \mathrm{msm} .882893$

Conflict of Interest: The authors declare that the research was conducted in the absence of any commercial or financial relationships that could be construed as a potential conflict of interest.

Publisher's Note: All claims expressed in this article are solely those of the authors and do not necessarily represent those of their affiliated organizations, or those of the publisher, the editors, and the reviewers. Any product that may be evaluated in this article, or claim that may be made by its manufacturer, is not guaranteed or endorsed by the publisher.

Copyright $(02022$ Sun, Qu and Zhao. This is an open-access article distributed under the terms of the Creative Commons Attribution License (CC BY). The use, distribution or reproduction in other forums is permitted, provided the original author(s) and the copyright owner(s) are credited and that the original publication in this journal is cited, in accordance with accepted academic practice. No use, distribution or reproduction is permitted which does not comply with these terms. 